\title{
ASSENTAMENTOS SUSTENTÁVEIS NA AMAZÔNIA: AVALIAÇÃO ECONÔMICA DO PROJETO DE DESENVOLVIMENTO SUSTENTÁVEL BONAL
}

\author{
Raimundo Cláudio Gomes Maciel ${ }^{1}$; Oleides Francisca de Oliveira ${ }^{2}$; Helen Cristina da Silva \\ Menezes $^{3}$; Gustavo Sóstenes Abreu Loureiro da Silva ${ }^{4}$; Amanda de Moura Almeida ${ }^{5}$; Ítalo \\ Henrique Bezerra da Silva ${ }^{6}$; Pedro Gilberto Cavalcante Filho ${ }^{7}$. \\ 1 - Doutor em Economia Aplicada (IE/UNICAMP), Professor do Centro de Ciências Jurídicas e Sociais \\ Aplicadas (CCJSA), Universidade Federal do Acre (UFAC). E-mail: rcgmaciel@ufac.br \\ 2 - Doutora em Desenvolvimento Regional (UNISC), Professora do Centro de Ciências Jurídicas e Sociais \\ Aplicadas (CCJSA), Universidade Federal do Acre (UFAC). E-mail: oleides.ufac@gmail.com \\ 3 - Graduanda em Economia, Universidade Federal do Acre (UFAC). E-mail: \\ hellencristyna51@gmail.com \\ 4 - Graduando em Economia, Universidade Federal do Acre (UFAC). E-mail: gustavo_sostenes@live.com \\ 5 - Graduanda em Economia, Universidade Federal do Acre (UFAC). E-mail: \\ amandademouraalmeida@gmail.com \\ 6 - Graduanda em Economia, Universidade Federal do Acre (UFAC). E-mail: \\ bitalohenrique98@gmail.com \\ 7 - Mestrando em Desenvolvimento Econômico pelo Instituto de Economia da Universidade Estadual de \\ Campinas (IE/UNICAMP). E-mail: pedro.gilberto@hotmail.com
}

\section{Resumo}

A luta pela posse da terra no Brasil levou à implantação de projetos de assentamentos dirigidos na região amazônica, a partir dos anos 1970. As dificuldades de reprodução das famílias assentadas ao longo do tempo e as discussões em torno do desenvolvimento sustentável induziu a novos modelos de assentamentos, como os Projetos de Desenvolvimento Sustentável (PDS) O PDS Bonal surgiu, em 2005, como um projeto inovador. O objetivo do presente trabalho é avaliar o desempenho econômico do PDS Bonal, em Senador Guiomard, Acre, nos últimos seis anos. Utilizase da metodologia do projeto ASPF, desenvolvido pela Universidade Federal do Acre (UFAC), a partir de indicadores de resultado econômico adequados à produção familiar rural. Os resultados indicam que, com o fechamento da agroindústria de palmito de pupunha, as famílias estão com imensas dificuldades de manutenção de suas necessidades, especialmente de gastos no mercado, levando ao endividamento.

Palavras-chave: Avaliação Econômica; Projetos de Desenvolvimento Sustentável; Amazônia; Agricultura Familiar. 
SUSTAINABLE SETTLEMENTS IN THE AMAZON:

ECONOMIC ASSESSMENT OF THE PROJECT

SUSTAINABLE DEVELOPMENT BONAL

\begin{abstract}
The struggle for land tenure in Brazil led to the implementation of settlement projects in the Amazon region beginning in the 1970s. The difficulties of reproducing settled families over time and the discussions about sustainable development induced new models of settlements such as Sustainable Development Projects (PDS) PDS Bonal emerged in 2005 as an innovative project. The aim of this work is to evaluate the economic performance of the PDS Bonal, in Senador Guiomard, Acre, in the last six years. The methodology of the ASPF project, developed by the Federal University of Acre (UFAC), is based on economic results indicators adequate to rural family production. The results indicate that, with the closure of the peach palm heartland agroindustry, families are facing great difficulties in maintaining their needs, especially in the market, leading to indebtedness.

Keywords: Economic Evaluation; Sustainable Development Projects; Amazon; Family Farming.

JEL: Q; Q15.
\end{abstract}




\section{INTRODUÇÃO}

Na década de 1970, por intermédio do INCRA foram criados, os primeiros projetos de assentamentos na Amazônia, especialmente os Projetos de Assentamentos Dirigidos (PADs), buscando aliviar as tensões sociais na luta pela posse da terra e viabilizar a agricultura familiar marginalizada em todas as regiões brasileiras. No entanto, com o passar do tempo a agricultura familiar ainda continuava com imensas dificuldades de reprodução, dados os problemas decorrentes de infraestrutura, crédito inadequado e insuficiente, falta de assistência técnica, etc.

No final dos anos 1990, novos modelos de assentamento são criados para encaminhar as questões não resolvidas pelos assentamentos anteriores. Nesse sentido, surgem os Projetos de Desenvolvimento Sustentável (PDS's), desenvolvidos para se estabelecer atividades ambientalmente sustentáveis e destinadas às populações tradicionais.

Em 2005, o INCRA criou o PDS Bonal, após a compra da fazenda Bonal, na qual encontrava-se instalada uma agroindústria que processava palmito de pupunha da região. Na área que o empreendimento estava instalado, haviam algumas famílias que residiam e trabalhavam na fazenda.

O PDS Bonal, desde sua criação, foi apontado como modelo de assentamento para a região, justamente porque solucionava questões cruciais identificadas nos antigos assentamentos: áreas já com plantios maduros, infraestrutura para escoamento da produção e, principalmente, uma agroindústria de palmito já em funcionamento para agregação de valor, trazendo resultados benéficos para a agricultura familiar.

Portanto, o objetivo do presente trabalho é avaliar os resultados econômicos das unidades produtivas das famílias assentadas no PDS Bonal, em Senador Guiomard, Acre, nos anos agrícolas de 2011/2012, 2012/2013, 2016/2017.

A importância do presente trabalho situa-se na sistematização de informações coletadas em campo para subsidiar tanto as políticas públicas para a região quanto à própria comunidade no sentido de corrigir possíveis equívocos e potenciar os benefícios proporcionados pelo assentamento. 


\section{REFORMA AGRÁRIA NA AMAZÔNIA}

A questão agraria no Brasil iniciou em 1530, ainda como colônia, quando a Coroa Portuguesa, ao criar as capitanias hereditárias e distribuir as terras do país em um sistema de sesmarias, exclusivamente para aqueles que tinha condição de cultiva-las, ocasionou o histórico processo de criação de grandes latifundiários, problema que aflige o país até os dias atuais (INCRA, 2011).

Com a perca do predomínio da Coroa Portuguesa sobre as terras brasileiras, em 1822, as terras que foram cedidas pelo sistema das sesmarias e que continuaram intactas tiveram que ser devolvidas. Com as terras em seu poder, o governo cria a Lei das terras, em 1850, sendo o primeiro projeto de organização da propriedade privada no Brasil. Essa lei estabelece que a ocupação de terras se daria unicamente por meio de compra através de arremates no leilão. Destarte, a criação desta imposição garantiu apenas os interesses dos grandes proprietários do Nordeste e do Sudeste (MACIEL et. al, 2016).

Os autores afirmam ainda que, com o decreto de abolição da escravidão, em meados de 1888, os exescravos desamparados, semianalfabetos e sem qualquer tipo de indenização, não tiveram acesso a terras, pois os mesmos não tinham condições de arremata-las.

De acordo com Maciel, Almeida e Menezes (2018), a gigantesca desproporção na distribuição de terras contribuiu para que grande parte da população ficasse desamparada, piorando, assim, a caótica situação social do país na época. Contudo, foi somente no final dos anos 50 e início dos anos 60 , com a industrialização do país, que a questão fundiária começou a ser discutida pela sociedade, que se urbanizava rapidamente.

Diante isso, surge, então, a Ligas Camponesas que, juntamente com o Movimento dos Trabalhadores Rurais Sem Terra, tinham o intuito de lutar pela redistribuição de terras no Brasil. Concomitantemente exerciam grande pressão sobre o Governo para tal reestruturação rural, reivindicando, principalmente, a ocupação de grandes propriedades improdutivas (MACIEL et. al, 2016).

Como resposta, o governo federal cria a Superintendência de Reforma Agrária (Supra). Assim, o regime militar deu o primeiro passo para a realização da reforma agrária no País. O Estatuto da Terra é escrito (Lei $\mathrm{n}^{\circ}$ 4.504, de 1964) e são criados o Instituto Brasileiro de Reforma Agrária — IBRA e o Instituto Nacional de Desenvolvimento Agrário - INDA, em substituição à Supra. Em 9 de julho de 1970, diante do decreto $\mathrm{n}^{\circ} 1.110$, houve uma fusão entre a IBRA e a INDA, resultando na criação do Instituto Nacional de Colonização e Reforma Agrária (MACIEL et. al, 2016). 
A instalação da ditadura militar, nos anos 1960, trouxe consigo o sonho do Brasil potência, sob o lema "integrar para não entregar", que resultou em buscar ocupar a Amazônia como forma de desenvolver a região e simultaneamente resolver a questão fundiária. Os incentivos para povoar a extensão amazônica desencadeou uma onda migratória que trouxe pessoas de vários estados do país, principalmente do Nordeste. A tentativa não obteve sucesso (MACIEL et. al, 2018).

A falta de orçamento e um profundo desgaste político acarretado pelas falhas tentativas paralisaram a reforma agrária (MACIEL et. al, 2016).

O projeto de desenvolver a Amazônia levou-a a profundas alterações econômicas e sociais. As políticas deliberadas provocaram o ingresso da agropecuária "desenvolvimentista" na região. Tais ações beneficiaram os "paulistas", responsáveis por introduzir as pastagens no lugar da estrutura florestal (MACIEL, 2007).

Também nessa época, começam as grandes obras rodoviárias em direção à Amazônia, como a Transamazônica, inaugurada em 1972 (INCRA, 2011).

$\mathrm{Na}$ análise de Maciel (2003; 2007), o desenvolvimento de infraestrutura na região atraiu os paulistas, acarretando em grandes conflitos contra os seringueiros pela posse de terra. Usando a lei do mais forte, os paulistas expulsavam os seringueiros de suas terras. Estes, então, iniciaram os chamados "empates", um movimento de resistência baseado na invasão das áreas dos novos proprietários afim de evitar o desmatamento para a formação de pastagens.

O processo de ocupação da Amazônia, que tinha como meta ocupar a região e sincronicamente amenizar a questão agraria, acabou ocasionando a formação de novos latifundiários e mais pessoas sem terras. Além disso, promoveu o desflorestamento e desestruturação da floresta amazônica (MACIEL, et. al, 2018).

Na década de 1970, por intermédio do INCRA foram criados, os primeiros projetos de assentamentos na Amazônia, especialmente os Projetos de Assentamentos Dirigidos (PADs), buscando aliviar as tensões sociais na luta pela posse da terra e viabilizar a agricultura familiar marginalizada em todas as regiões brasileiras. No entanto, com o passar do tempo a agricultura familiar ainda continuava com imensas dificuldades de reprodução, dados os problemas decorrentes de infraestrutura, crédito inadequado e insuficiente, falta de assistência técnica etc. (MACIEL et. al, 2016). 


\section{CRIAÇÃO DOS ASSENTAMENTOS SUSTENTÁVEIS NA AMAZÔNIA}

No final dos anos 1990, novos modelos de assentamento são criados para encaminhar as questões não resolvidas pelos assentamentos anteriores. Dentre esses assentamentos se pode citar os Projetos de Desenvolvimento Sustentável (PDS), que tinha como objetivo promover um novo modelo de reforma agrária, propondo às famílias assentadas a responsabilidade pela preservação ambiental, usando de forma consciente e adequada os recursos da floresta, baseado em um sistema cooperativista, além disso, buscando autossuficiência econômica, ambiental e social (MACIEL et al., 2017).

Para Veiga (2001) o que faltam nesses assentamentos são as articulações intermunicipais que ajudem no diagnóstico para identificar os problemas rurais, planejamento de desenvolvimento integrado e na captação de novos recursos. Além disso, o autor salienta que "o papel dos governos federais e estaduais deve ser o de estimular iniciativas que no futuro poderão ser autofinanciadas, mas que dificilmente surgirão, ou demorarão muito para surgir, se não houver o indispensável empurrão inicial." (2001, p. 111). O autor propõe que nas fases de diagnóstico e planejamento, a ajuda governamental poderá ter mais impacto se envolver uma alocação temporária de recursos humanos com a capacitação necessária. Por exemplo, financiando grupos de pesquisas de universidades e de outros centros de pesquisa, para auxiliarem as articulações intermunicipais.

Os primeiros PDS's foram implantados pelo INCRA com base nos pressupostos do desenvolvimento sustentável desenvolvidos pela Comissão Mundial sobre Meio Ambiente e Desenvolvimento (CMMAD), em 1988. Essa discussão influenciou também na questão agrária brasileira, pensando em novas modalidades de assentamentos na Amazônia.

A produção de um PDS está baseada na atividade extrativista dos recursos florestais. Tem como objetivo tornar a produção eficiente a partir dos sistemas agroflorestais e buscando maior aproveitamento do solo com plantios consorciados. Tendo, assim, maior variedade de produção. Desta forma, o PDS Bonal é fruto dessa nova concepção de assentamento, tendo o objetivo de seguir os pressupostos de desenvolvimento sustentável, além de trabalhar uma nova forma de gestão na extração dos recursos naturais, especialmente de forma coletiva, comunitária. 
Para Maciel et al. (2017), o diferencial deste assentamento é a forma da implantação. Depois do desinteresse dos proprietários da agroindústria de palmito, após reivindicações de antigos funcionários para que houvesse um processo de reforma agrária na região, o INCRA adquiriu a área por meio de negociação e compra com os empresários. O que se evidencia é que foi uma maneira de evitar que as famílias fossem para os centros urbanos em busca de uma "vida melhor", assim, evitando um novo êxodo rural, além de promover o desenvolvimento nesse campo.

As populações tradicionais são caracterizadas pela organização em grupo de pessoas de pequenos produtores, atraídos por uma atividade econômica. Para eles, a natureza desempenha um papel significativo na definição e desenvolvimento de modos de vida específicos, geralmente em sintonia com as regras básicas do ecossistema florestal. Assim, adquirem conhecimento profundo dos ciclos biológicos da natureza e desenvolvem tecnologias simples, porém, adaptadas ao seu modo de vida e à lógica do ambiente. Finalmente, deve-se ressaltar que essas comunidades desenvolvem sua própria cultura, rica em conhecimento que envolve as leis da natureza (DIEGUES, 2001 apud MACIEL et al., 2017).

\section{AGRICULTURA FAMILIAR NA AMAZÔNIA}

A agricultura familiar se caracteriza quando a família é simultaneamente a proprietária dos meios de produção e assume o trabalho nas unidades produtivas. Deste modo, todas as técnicas utilizadas na produção são definidas pelos próprios produtores rurais, os quais se utilizam de seus conhecimentos tradicionais em todos os tratos culturais, desde a escolha do local onde será feita a plantação, a maneira como será preparado o solo, as formas de colheita, até o planejamento de como será comercializado o produto final (WANDERLEY, 2003).

Desse modo, a autora enfatiza que o termo agricultor familiar teria caráter genérico, incluindo diferentes situações produtivas executadas por núcleos familiares rurais. Entre elas, seria possível identificar aquela tradicionalmente denominada como camponesa. Os vínculos da produção agrícola familiar à economia seriam um reflexo da capacidade de adaptação da organização camponesa diante das transformações da sociedade. Com isso, é necessária uma adaptação desses camponeses que vieram de uma forma de produção de autoconsumo, para uma agricultura que visa geração de renda e múltiplas culturas. 
Mas, para que esse processo ocorra de forma positiva, é necessário o apoio político nessa transformação. No primeiro momento o grande parceiro é o governo federal por meio de distribuição de terras na criação de assentamentos regularizados pelo Instituto Nacional de Colonização e Reforma Agraria - INCRA.

Desta forma, essa discussão enseja debates que buscam alternativas produtivas capazes de transformar a produção dos pequenos agricultores em atividades viáveis que garantam a reprodução social no meio rural, através de programas de reforma agraria.

De acordo com Mendras (1984, p. 164) “o agricultor não é mais seu próprio mestre e necessita, permanentemente, de um mestre para instruí-lo". Nesse sentido, a reprodução da agricultura familiar depende claramente da mudança do paradigma da modernização da agricultura, como principal política de geração de renda e desenvolvimento comunitário, para um novo paradigma do desenvolvimento rural, buscando-se um novo padrão para o meio rural, porém ajustado a cada região e realidade em que se encontram as famílias rurais. (MACIEL e CAMPOS, 2011.p. 6).

No envolvimento desse novo paradigma, na Amazônia, o Instituto de Pesquisa Ambiental da Amazônia - IPAM, implantou o projeto "Assentamentos na Amazônia" que traz como objetivo o fortalecimento das organizações locais, para que não sejam meros recipientes de propostas externas fortalecendo-se essas instituições, acredita-se que haja sustentabilidade das ações exercidas nas comunidades por elas contempladas, uma vez que se fortalecerão e terão capacidade de captação própria de recursos.

De acordo com Pinto (2013), a atuação do IPAM sempre foi pautada pelo cuidado de construção das iniciativas em conjunto, envolvendo todos os seus stakeholders, sem o objetivo de obter méritos individualmente. Com isso, consegue-se legitimação e apoio das partes para as ações em todo o seu processo - por meio da construção conjunta, no sentido de criação de parceiros duradouros. O autor destaca ainda que, todas as ações do IPAM junto aos beneficiários são planejadas com o envolvimento das organizações locais, lideranças rurais e sindicais.

Esse apoio é fundamental para que essas famílias permaneçam em suas áreas de forma digna, proporcionando também um aumento na economia da região, já que os produtos produzidos serão vendidos a um preço mais razoável a todos, diminuindo assim o nível de pobreza (Maciel et al., 2017). 
No entanto, Dombek (2006) já dizia que os pequenos agricultores possuem dificuldades em desenvolver as suas produções através de novas tecnologias, pois requer mais conhecimento técnico e necessária adaptação. Isso implicará na dificuldade na geração de renda e consequentemente não arcam com as suas dívidas, tendo que vender e procurar outro lugar para morar, sendo drasticamente expulsos do meio rural.

Para Maciel et al (2017) para o desenvolvimento sustentável nos assentamentos na Amazônia, az necessário uma adaptação às novas tecnologias, pois com a evolução da produção os pequenos produtores teriam a chance de concorrer no mercado consumidor de produtos agrícolas. Entretanto, alguns agricultores se perdem nesse meio por não conseguirem se adaptar as inovações tecnológicas.

\section{METODOLOGIA}

A metodologia utilizada nesse trabalho, foi desenvolvida pelo Projeto de pesquisa Análise Econômica de Sistemas de Produção Familiar Rural no Estado do Acre, denominado ASPF, pelo Departamento de Economia da UFAC, desde 1996.

O objeto de estudo do presente trabalho são as famílias assentadas no PDS Bonal, criado através do processo $N^{\circ}$. 021, em 05/07/2005 e publicado através da Portaria $\mathrm{n}^{\circ}$. 45/98 em 24/03/2005. Possui uma área total de 10.447 ha (dez mil, quatrocentos e quarenta e sete hectares), está localizado no Estado do Acre, no município de Senador Guiomard, às margens da BR-364, km 76, com capacidade para assentar 210 famílias (INCRA, 2010).

A metodologia adotada foi pesquisa de campo, trazendo um levantamento de dados realizados pelo questionário pré estruturado, aplicado em entrevista aos moradores do PDS Bonal.

Os levantamentos socioeconômicos foram realizados por meio de amostragem, sendo sorteados aleatoriamente $10 \%$ dos produtores — do total de 210 assentados —, ponderados pela população assentada nos conglomerados existentes no PDS, sendo três Agrovilas: Bom destino, Retiro e Morada Nova além de produtores que moram na própria floresta do assentamento, pelo qual foram entrevistados e preenchido um questionário com questões fechadas, pré-elaboradas. 
Os principais indicadores econômicos são sucintamente descritos a seguir:

\begin{tabular}{|c|c|c|c|}
\hline \multicolumn{4}{|l|}{ 1) RESULTADO BRUTO } \\
\hline Indicador & Definição & Formula & Descrição \\
\hline Renda Bruta (RB) & $\begin{array}{l}\text { Indicador de escala de } \\
\text { produção }\end{array}$ & $R B=Q m \times p p$ & $\begin{array}{l}Q m=\text { Quant. do Produto } \\
\text { Destinada ao Mercado; } \\
P p=\text { Preço Unit. ao Produtor. }\end{array}$ \\
\hline \multicolumn{4}{|l|}{ 2) Resultados Líquidos } \\
\hline Indicador & Definição & Formula & Descrição \\
\hline Renda Liquida (RL) & Excedente apropriado & $R L=R B-D E$ & $\begin{array}{l}R B=\text { Renda Bruta; } \\
D E=\text { Despesas Efetivas. }\end{array}$ \\
\hline Lucro da Exploração (LE) & $\begin{array}{l}\text { Possibilidade de } \\
\text { acumulação }\end{array}$ & $L E=R B-C T$ & $\begin{array}{l}R B=\text { Renda Bruta; } \\
\mathrm{CT}=\text { Custos Totais }\end{array}$ \\
\hline Margem Bruta Familiar (MBF) & $\begin{array}{l}\text { Vr. monetário disponível } \\
\text { para a família }\end{array}$ & $\begin{array}{l}M B F=R B-(C V \\
-c f t)\end{array}$ & $\begin{array}{l}R B=\text { Renda Bruta; } \\
C V=\text { Custos Variáveis; } \\
C f t f=\text { Custo Real da Força de } \\
\text { Trabalho Familiar. }\end{array}$ \\
\hline Nível de Vida (NV) & $\begin{array}{l}\text { Indicador monetário do } \\
\text { padrão de vida }\end{array}$ & $\begin{array}{l}N V=(M B F+A C \\
+C j i c c)-A A\end{array}$ & $\begin{array}{l}M B F=\text { Margem bruta } \\
\text { familiar; } \\
A C=\text { Autoconsumo; } \\
C j i c c=\text { Juros Imputados ao } \\
\text { Capital Circulante; } \\
A A=\text { Amortizações Anuais de } \\
\text { Empréstimos. }\end{array}$ \\
\hline
\end{tabular}

\section{3) Medidas de Relação}

\begin{tabular}{|c|c|c|c|}
\hline Indicador & Definição & Formula & Descrição \\
\hline $\begin{array}{l}\text { Índice de remuneração da mão de } \\
\text { obra familiar (MBF/Qh/d) }\end{array}$ & $\begin{array}{l}\text { Índice de apropriação da } \\
\text { RB pelo mercado }\end{array}$ & $T I=\frac{V B C C}{R B}$ & $\begin{array}{l}T I=\text { Termo de Intercâmbio; } \\
V B C C=\text { Valor dos Bens de } \\
\text { Consumo Comprados; } \\
R B=\text { Renda Bruta Total. }\end{array}$ \\
\hline
\end{tabular}

4) Linha de Dependência do Mercado

Definem-se como linha de dependência do mercado os valores medianos gastos com bens e serviços de consumo no mercado, adicionados das compras relacionadas à reposição do capital fixo (máquinas, equipamentos, ferramentas, benfeitorias etc.) disponível para a manutenção dos meios de produção existentes.

\section{5) Eficiência Econômica}

\begin{tabular}{|l|l|l|l|}
\hline $\begin{array}{l}\text { Índice de Eficiência Econômica } \\
\text { (IEE) }\end{array}$ & $\begin{array}{l}\text { Indicador de } \\
\text { benefício/custo }\end{array}$ & $I E E \times \frac{R B}{C T}$ & $\begin{array}{l}R B=\text { Renda Bruta; } \\
C T=\text { Custos Totais. }\end{array}$ \\
\hline Resultado: & $\begin{array}{l}\text { IEE > 1, a situação é de } \\
\text { lucro. }\end{array}$ & $\begin{array}{l}\text { IEE < 1, a situação } \\
\text { é de prejuízo. }\end{array}$ & $\begin{array}{l}\text { IEE }=\mathbf{1 , ~ a ~ s i t u a c ̧ a ̃ o ~ e ́ ~ d e ~} \\
\text { equilíbrio. }\end{array}$ \\
\hline
\end{tabular}

Fonte: Projeto de Pesquisa Análise Econômica de Sistemas de Produção Familiar Rural - ASPF, 1996. 
Atendendo ainda aos objetivos da pesquisa, buscou-se trabalhar a metodologia a partir de indicadores e índices socioeconômicos que levem em consideração as particularidades da região de estudo e sirvam como parâmetros para relacionar as diversas regiões e determinadas formas técnicas produtiva dos produtos comercializados, considerando os levantamentos realizados no período referentes aos anos agrícolas de 2011/2012, 2013/2014 e comparando com os resultados do período mais recente, 2016/2017, e indicando as prioridades de atuação para um efetivo desenvolvimento socioeconômico sustentável.

\section{RESULTADOS E DISCUSSÕES}

O PDS Bonal surgiu com boas perspectivas de inovação em relação a projetos de assentamentos tradicionais, pois em sua área já havia plantios de seringueira e pupunha, além de uma agroindústria de palmito de pupunha, com excelentes referências de mercado.

Quando o PDS Bonal foi implantado, definiu-se que as famílias exerceriam o trabalho em um sistema coletivo, e assim, os resultados seriam divididos entre os produtores da região. No entanto, devido alguns problemas na parte de distribuição equitativa, fez-se pensar em novas alternativas de gestão. Dessa forma, a área do PDS foi dividida em lotes, dos quais cada família assentada teve direito a exploração de 08 (oito) ha de terra, obtidas por meio de concessão de uso. Assim, a produção passou a ser individualizada, embora uma parte da área de floresta ainda seja de uso coletivo.

Nas entrevistas do período 2011/2012 estudado, observou-se, entre as famílias assentadas, a presença de pessoas deslocadas ao processo produtivo, assim, desenvolvendo atividades fora do assentamento. Haviam famílias que dependiam exclusivamente de fontes externas de recursos - algumas delas utilizando basicamente a área como dormitório.

Por outro lado, durante as entrevistas no segundo período, 2012/2013, foi observado que o processo de desocupação das terras de algumas famílias assentadas no PDS Bonal intensificou-se ainda mais, vendendo seus lotes para outros produtores e migrando para as cidades, permanecendo no assentamento aquelas famílias com perfil de produtores rurais.

Durante as pesquisas, verificou-se algumas questões sociais que podem impactar no desenvolvimento do projeto, notadamente em relação à drogas, alcoolismo e gravidez na adolescência, tão comuns à diversos bairros periféricos das cidades do entorno, que precisam de pesquisas para um diagnóstico efetivo sobre os temas. 
Do ponto de vista ambiental, verificou-se sérios problemas em relação aos desflorestamentos clandestinos e, consequentes queimadas, realizados tanto por invasores de outras áreas quanto por alguns moradores da floresta.

Do ponto de vista econômico, cuja avaliação está nos objetivos do presente trabalho, uma questão crucial que impactou decisivamente no desempenho das famílias foi o fechamento da agroindústria de palmito de pupunha, em 2012, em virtude de problemas financeiros relacionados à gestão do empreendimento por parte da cooperativa de produtores, justamente no ano em que se começou as pesquisas na região, impactando decisivamente na geração de renda dos produtores.

No gráfico 1, é apresentada a geração por produto de renda bruta no PDS Bonal. Nota-se a evolução de alguns dos produtos analisados, como o açaí e a macaxeira, que nos três períodos pesquisados, como importantes geradores de renda bruta dentro da comunidade, apresentaram um aumento significante na produção familiar.

Grafico 1 - Geração por produto de renda bruta no PDS Bonal - Senador Guiomard - Acre 2011/2012, $2012 / 2013$ e 2016/2017.

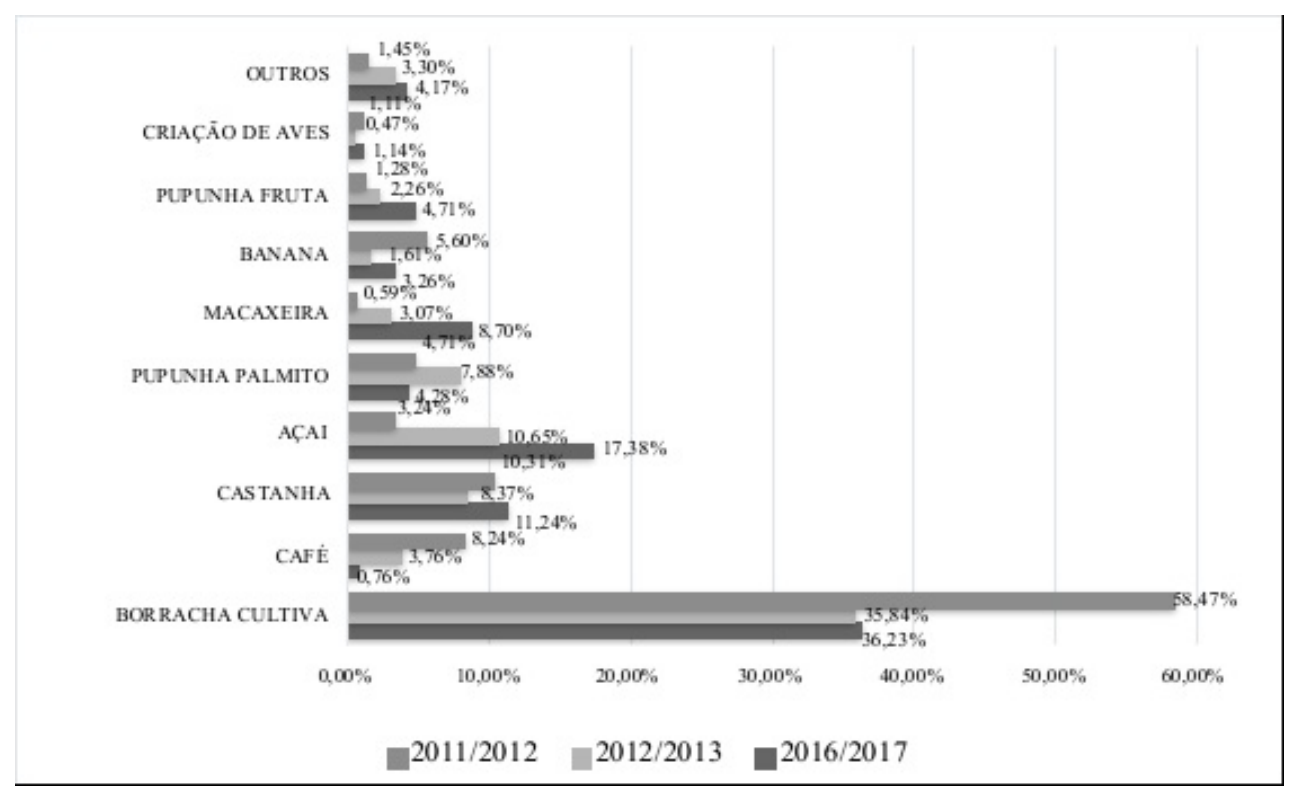

Fonte: ASPF (2019). 
Ademais, é importante destacar que a borracha foi altamente explorada no período do fechamento da agroindústria, respondendo por quase $60 \%$ de toda a renda gerada no projeto, No entanto, a estabilidade de geração de renda apresentada no período entre 2012/2013 e 2016/2017 indica o real potencial da produção de borracha, sendo necessária a diversificação da produção, como o açaí, a macaxeira e a pupunha que passaram a ser produzidos e comercializados pelas famílias como forma alternativa de renda.

Cabe destacar que o palmito de pupunha que aparece na geração de renda, mesmo com a falência da agroindústria, foi comercializado fora do PDS Bonal para outra agroindústria da região, a quase 100 quilômetros de distância e com capacidade limitada de processamento.

Por outro lado, as famílias enfrentam dificuldades de diversificação produtiva, pois as áreas produtivas são quase que totalmente ocupadas com os plantios de borracha e palmito. Além disso, alguns produtos alternativos são produzidos na floresta da região, a partir de árvores nativas, limitadas pela quantidade disponível na floresta.

Conforme a Tabela 1, pode-se avaliar o desempenho econômico das famílias do PDS Bonal. Um primeiro aspecto a observar são os baixos rendimento auferidos tanto pela renda bruta (RB) quanto pela margem bruta familiar (MBF), que é o valor apropriado pelos produtores depois de descontados os custos imediatos, no período recente, cuja redução nos últimos seis anos gira em torno de $30 \%$. Isto demonstra que a diversificação produtiva não surtiu o efeito desejado, dadas os produtos, quantidades e preços trabalhados, levando à ineficiência produtiva (IEE menor que 1) e maior dependência do mercado, com endividamento.

Cabe destacar, ainda na Tabela 1, os rendimentos obtidos no período de 2012/2013, pois a renda bruta mediana das famílias quase iguala o valor do salário mínimo mensal do país. Esse resultado evidencia o papel do palmito de pupunha na geração de renda, bem como da agroindústria fechada, pois, de acordo com o gráfico 1, o palmito vendido foi quase o dobro em relação aos outros períodos analisados. 
Tabela 1 - Indicadores de desempenho econômico entre as famílias do PDS Bonal, Acre - 2011/2012, 2012/2013 e 2016/2017.

\begin{tabular}{c|c|c|c|c|c|c}
\hline Indicadores Econômicos & Unidade & $\mathbf{2 0 1 2}$ & $\mathbf{2 0 1 3}$ & $\mathbf{2 0 1 7}$ & $\begin{array}{c}\text { Evolução } \\
\text { de 2012 - } \\
\mathbf{2 0 1 7}\end{array}$ & $\begin{array}{c}\text { Evolução } \\
\mathbf{2 0 1 3} \\
\mathbf{2 0 1 7}\end{array}$ \\
\hline RB - Renda Bruta & R \$mês & 452,98 & 945,19 & 329,66 & $-27,22 \%$ & $-65,12 \%$ \\
\hline MBF - Margem Bruta Familiar & R\$ /mês & 404,22 & 939,73 & 273,37 & $-32,37 \%$ & $-70,91 \%$ \\
\hline $\begin{array}{c}\text { VBCC - Bens de Consumo } \\
\text { Comprados no Mercado }\end{array}$ & R\$ /mês & 824,2 & 921,57 & 1488,69 & $80,62 \%$ & $61,54 \%$ \\
\hline AC - Autoconsumo & R\$ /mês & 114,43 & 166,93 & 56,06 & $-51,01 \%$ & $-66,42 \%$ \\
\hline NV - Nível de Vida & R\$ /mês & 471,93 & $1.125,35$ & 333,64 & $-29,30 \%$ & $-70,35 \%$ \\
\hline $\begin{array}{c}\text { IEE - Índice de Eficiência } \\
\text { Econômica }\end{array}$ & und. & 0,83 & 1,46 & 0,95 & $15,38 \%$ & $-34,41 \%$ \\
\hline MBF/RB & und. & 0,9 & 0,94 & 0,86 & $-3,59 \%$ & $-7,69 \%$ \\
\hline
\end{tabular}

Obs.: Resultados medianos por UPF (Unidade Produtiva Familiar); *Atualização monetária até março de 2019 (INPC/IBGE).

Fonte: ASPF (2019).

Tal resultado permitiu aos produtores a ter lucro no processo produtivo, com IEE maior que 1, satisfazer suas necessidades de consumo no mercado, além de elevar o nível de vida, em termos monetários, superior em 13\%, no período de 2012/2013.

Um aspecto importante que pode ter levado ao baixo desempenho econômico do período recente, observado durante as pesquisas, foi o desânimo dos produtores com fechamento da agroindústria de palmito e as dificuldades de manter os plantios, levando a um processo de desinvestimento na cultura da pupunha.

Assim, a ineficiência econômica das atividades está levando aos baixos rendimentos, baixo autoconsumo, que leva à maior dependência de consumo no mercado. Por conseguinte, os rendimentos produtivos não são suficientes para a aquisição de produtos no mercado e está levando a um processo de endividamento das famílias. Ou seja, as famílias estão buscando assalariamento fora das unidades produtivas e dependendo cada vez mais de transferências governamentais. 
Uma informação importante é que uma nova agroindústria de palmito de pupunha está sendo concluída, bem como a aquisição de novos equipamentos, sob uma nova gestão de uma cooperativa bem conhecida na região. Talvez esse novo empreendimento possa representar um novo recomeço para as famílias do PDS Bonal e todo o processo sirva de aprendizado para reorganizar as forças produtivas da região.

\section{CONSIDERAÇÕES FINAIS}

Os recorrentes debates sobre o desenvolvimento sustentável, surgidos nos anos 80, trouxeram consigo, a percepção da importância da elaboração de alternativas de desenvolvimento que pudessem atingir esse objetivo. Com isso, surge, também, no Brasil a irresoluta questão agrária. Para tanto, foram pensadas em novas modalidades de assentamentos na Amazônia.

Destarte, criaram os Projetos de Desenvolvimento Sustentável (PDS) com o intuito de que fossem utilizados os recursos florestais de maneira social e ambientalmente responsável. A produção de um PDS está baseada na exploração dos recursos naturais, como atividades econômicas e autoconsumo, de forma consciente.

Logo, o PDS Bonal nasce dessa nova concepção de assentamento, trabalhando uma nova forma de gestão na extração dos recursos naturais de forma coletiva e comunitária, com o intuito de seguir os pressupostos de desenvolvimento sustentável.

Verificou-se que esse PDS era tido como promissor, visto sua estrutura física. No entanto, não foi levado em consideração que muitas estruturas estavam obsoletas, principalmente, a agroindústria e o plantio de pupunha, além de carência nos serviços de assistência técnica.

Produtivamente, em 2011/2012, as famílias assentadas no PDS se especializaram, em especial, na produção de dois produtos: a borracha e o palmito pupunha. No entanto, no ano de 2012, a agroindústria parou com as atividades, devido à má gestão dos cooperados. Assim, a maioria dos assentados sentiu o impacto dessa situação por enfatizar a produção no palmito de pupunha. O que se viu foi pouca produção na agricultura, mostrando uma forte dependência com o mercado externo. 
Em 2012/2013, observou-se que apesar de os produtos considerados como "eminentes" continuarem a ter importante papel na geração de renda entre as famílias, houve uma diversificação da produção com produtos mais valorizados no mercado, como o café, como também foram apresentados produtos que são da chamada "lavoura branca" - a macaxeira, por exemplo. Contudo, não foi o bastante para resolver o problema com a dependência externa, pois a produção na agricultura ainda era insuficiente.

Com o fechamento da agroindústria Bonal, no ano de 2012, os produtores tiveram que comercializar sua produção para outras agroindústrias, para isso, houve um maior esforço na produção, consequentemente, sucedeu um resultado positivo, dado que houve um aumento nos principais indicadores econômicos, como a renda bruta e a margem bruta familiar, além de aumentar o nível de vida e o índice de eficiência econômica.

Passando esse período, a partir do ano de 2016, houve um acentuado declínio na produção, fato que pode ser explicado pela incapacidade dos produtores em manter o nível de produção elevado e, assim, abandonarem o cultivo de algumas culturas. Dessa forma, os indicadores econômicos atuais mostram que a falta de uma eficiente gestão da agroindústria da Bonal está causando graves danos às famílias dependentes.

Assim, é evidente que a situação das famílias no PDS Bonal piorou ao comparar o primeiro momento com o atual. Porém, com planejamentos adequados, esses problemas podem ser solucionados. Inicialmente, os gestores devem estar qualificados para gerir o assentamento, reativando a agroindústria instalada e regulamentando a produção. Posteriormente, os produtores devem se conscientizar que o uso e a gestão dos recursos naturais é a melhor maneira para terem uma vida digna e continuar trabalhando com a diversificação de produtos. Desta forma, poderá se alcançar um efetivo desenvolvimento sustentável no PDS Bonal.

\section{REFERÊNCIAS}

ASPF - Análise Socioeconômica de Sistemas Básicos de Produção Familiar Rural no Estado Acre. 2019. Disponível em: < http://aspf.wordpress.com/>. (Projeto de Pesquisa do Centro de Ciências Jurídicas e Sociais Aplicadas da UFAC).

CMMAD - Comissão Mundial sobre Meio Ambiente e Desenvolvimento. Nosso futuro comum. 2a ed. Tradução de Our common future. 1a ed. 1988. Rio de Janeiro: Editora da Fundação Getúlio Vargas, 1991. 
DIEGUES, Antonio Carlos. O Mito Moderno da Natureza Intocada. São Paulo: Hucitec/NUPAUB-USP, 2001.

DOMBEK, Luiz Antonio. Autoconsumo e Segurança Alimentar em Assentamentos Rurais do Pontal do Paranapanema. Dissertação de Mestrado submetida à banca examinadora para obtenção de título de mestre em Engenharia Agrícola. 2006. UNICAMP. Campinas - SP.

INSTITUTO DE PESQUISA AMBIENTAL DA AMAZÔNIA - IPAM. Website do projeto Assentamentos Sustentáveis na Amazônia. Disponível em: http://assentamentosustentavel.org.br. Acesso em 29. 06. 2013.

INCRA - Instituto Nacional de Colonização e Reforma Agrária. Histórico da questão agrária. 2011. Disponível em: http://www.incra.gov.br/index.php/reforma-agraria-2/questao-agraria/historico-daquestao-agraria. Acesso em: 20/11/2017.

MACIEL, R. C. G.; Certificação Ambiental: Uma Estratégia para Conservação da Floresta Amazônica. IE/UNICAMP. 2007. 195p. (Tese apresentada ao Instituto de Economia da UNICAMP como requisito parcial para a obtenção do título de doutor em Economia. Campinas - SP).

; Ilhas de Alta Produtividade: Inovação Essencial para a Manutenção dos Seringueiros nas Reservas Extrativistas. UNICAMP. 2003. 98p. (Dissertação apresentada ao Instituto de Economia da UNICAMP como requisito parcial para a obtenção do título de Mestre Desenvolvimento Econômico, Espaço e Meio Ambiente. Campinas - SP.

; CAVAlCANTI, F. C. F.; SOUZA, E. F.; FILHO, P. G. C.; A reserva extrativista "Chico Mendes" e a governança fundiária na Amazônia: algumas lições das duas últimas décadas. In: III Seminário Internacional de Governança de Terras e Desenvolvimento Econômico: Regularização Fundiária, III. 2017, UNICAMP. Anais... Campinas, 2017.

; ALMEIDA, A. M.; MENEZES, H. C. S. Avaliação econômica da pecuária de gado bovino na Reserva Extrativista (RESEX) Chico Mendes. In: Congresso da Sociedade Brasileira de Economia, Administração e Sociologia Rural, 56. 2018, UNICAMP. Anais... Campinas: SOBER, 2018. ; CAVALCANTI, F. C. DA S.; SOUZA, E. F.; OLIVEIRA, O. F.; CAVALCANTE FILHO, P. G. The -Chico Mendes- extractive reserve and land governance in the Amazon: Some lessons from the two last decades. Journal of Environmental Management, v. 223, p. 403-408, 2018.

; CAVALCANTE FILHO, P. G.; SOUZA, D. L.; MARÇAL, G. W. da S. ; SOARES,

SARAH C. C. Agricultura familiar em assentamentos na Amazônia: desempenho econômico das famílias no projeto de desenvolvimento sustentável Bonal, Acre. Ciências Sociais em Perspectiva, v. 16, p. 146164, 2017.

; CAMPOS, K. P. da C.; Agricultura Familiar no Acre: Considerações a partir do 
Censo agropecuário 2006. In: Congresso da Sociedade Brasileira de Economia, Administração e Sociologia Rural, 49. 2011, Belo Horizonte. Anais... Belo Horizonte: SOBER, 2011.

MENDRAS, Henri. La fin des paysans; suivi d'une refléxion sur La fin des paysans vingt ans après. Paris, Actes Sud, 1984. 437 p.

PINTO, Erika de Paula Pedro. Entrevista concedida a Denise Imori, em 11 de junho de 2013.

VEIGA, José Eli da. O Brasil rural ainda não encontrou seu eixo de desenvolvimento. Estudos Avançados N. 15 (43), 2001.

WANDERLEY, M. de N. B., Agricultura familiar e campesinato: rupturas e continuidade. Estudos Sociedade e Agricultura, Rio de Janeiro, n. 21, p. 42-61, out. 2003. 